\title{
Dynamic Analysis and Determination of Maximum Tensile Strain of Bottom Asphalt Concrete for Different Vehicle Velocities
}

\author{
Gholamali Shafabakhsh $^{\mathrm{a}, *}$, Hossein Naderpour ${ }^{\mathrm{b}}$, and Mana Motamedi ${ }^{2, \mathrm{c}}$ \\ Faculty of Civil Engineering, Semnan University, Semnan, I.R. of Iran \\ E-mail: ashafabakhsh@semnan.ac.ir (Corresponding author), bnaderpour@semnan.ac.ir, \\ cmana.motamedi@gmail.com
}

\begin{abstract}
Studying the stress, strain and deformation in pavement under traffic loads is one of the most important areas in pavement engineering. Tensile strain in the bottom of asphalt, leads to the most common type of failure (fatigue); therefore, it is an important parameter to be analyzed. In this study, the pavement structure has been analyzed and then for validation, the output in all elements and points were compared to the field results obtained from University of Pennsylvania. The further studies were conducted by $3 \mathrm{D}$ program which indicated a good agreement with the results from field and the first finite elementbased program. In static and quasi-static loadings, the maximum strain were observed exactly under the load center, while in dynamic loading, unexpectedly, the maximum value occurred behind the load center, and the distance increases by increase of vehicle velocity. This study includes the effect of load speed on tensile strain in asphalt sub-layer.
\end{abstract}

Keywords: Dynamic analysis, longitudinal tensile strain, flexible pavement, load speed, finite element.

ENGINEERING JOURNAL Volume 19 Issue 4

Received 25 July 2014

Accepted 7 January 2015

Published 31 July 2015

Online at http://www.engj.org/

DOI:10.4186/ej.2019.19.4.107 


\section{Introduction}

Knowledge of the maximum values of stress and strain generated in the pavement and determining its exact location would improve the quality of analysis and design. In recent decades, engineers have begun to use numerical methods. Elastic layers theory of road pavement is one of the oldest methods of analysis which has been used by many engineers [1]. With the progress of science and the creation of the finite element method, some limitations of elastic layers method became apparent. Then, the finite element method was used to simulate the road pavement structure and its loading. Layered system is not able to analyze the dynamics of the wheels and the ability to model the types of axles, wheels and dynamic motion is weak [2]. In 1993, Zaghloul and White studied the road pavement dynamic responses and observed a good agreement between the results of Abaqus and field measurements at three different speeds [3]. Abaqus software as a finite element program was extensively used for the analysis of road pavement. Other study by Chen and colleagues showed that the results of this application, is comparable with those of other software [4]. Thus, determining the dynamic response of road pavement is very important in the analysis and design. In this study dynamic Modeling at different velocities for tandem axles with paired wheels has been performed and coordinates of critical points where strain maximum occurs, have been studied and correspondent charts and tables are provided.

\section{Research Background}

Loading vehicles is usually a static model but research result has shown that the response of pavement is affected by moving wheel [5]. Developed solutions led to pay more attention to the problem of dynamic response of pavement under traffic load [6].

Usually in quasi -static and static analysis, unlike the inertia dynamics, mass and damping forces are not considered. Research shows that fatigue failure in dynamic mode can be up to 4 times in quasi-static [7].

So far, many researches in the field of asphalt concrete behavior analysis and determining the maximum stress and strain values have been carried out that most of them are static and modelling of pavement is in poor condition. The results show that in static mode, the maximum strain at the bottom of the asphalt layer emerges in the wheel center [8].

The effect of a moving load on pavement response is important and should be considered [9]. In 1992, Lawrence found that the stress and flexural deformation of pavement in dynamic and static loads are substantially different with each other and pavement stress value after load passing is dependent on the loading speed [10]. Mamlouk and Davies (1984) concluded that dynamic deflections under falling weight deflectometer (FWD) tests were greater than the corresponding static displacements [11].

Cebon and Hardy found that the effect of loading frequency on pavement strain is relatively minor compared with the effect of loading rate [12].

\section{Research Methodology}

Up to now, many researches in the field of asphalt concrete behavior analysis and determining the maximum stress and strain values have been done. These studies include determining the maximum strain generated in the pavement, identifying the best meshing, the optimal dimensions of model and type of loading. A comprehensive analysis in the field of the coordinates of the maximum strains and stresses has not taken place yet. Investigating the exact location of the maximum strain will be discussed in this study. To achieve this goal, a dynamic analysis of the pavement along with the boundary conditions and accurate meshing has been done by using Abaqus software. In order to validate the model, data and the field results of Pennsylvania are used.

\section{Dynamic Analysis and Determining the Location of the Maximum Tensile Strain of Asphalt Layer}

Since 1986, with the creation of finite element method, a great development arises in the pavement analysis and design. Due to the limitations of the mechanistic and multi layered approaches, many of the engineers utilize the finite element method to simulate the pavement structure which it provides better conditions for the pavementdynamic analysis [6]. However, finite elements model is an approximate method and its 
accuracy highly depends on meshing and user's experience [13]. Next research, in 1984, showed that finite element analytical method presents more accurate results than layered elastic theory [14]. In the following section, determination of the coordinates of the maximum tensile strain of asphalt sub-layer will be discussed.

\subsection{Theoretical Foundations of Dynamic Analysis}

According to the elasto-dynamic theory, the governing equation of the dynamic response of a multilayer system can be written as follows:

$$
M\{\ddot{\boldsymbol{u}}\}+C\{\dot{\boldsymbol{u}}\}+K\{\boldsymbol{u}\}=P(t)
$$

Dynamic analysis considers the effects of mass inertia and damping forces, Where $u, \dot{u}$ and $\ddot{u}$ are the vectors of displacement, speed and acceleration related to the nodes, respectively. Also $\mathrm{M}, \mathrm{C}$ and $\mathrm{K}$ are mass, damping and stiffness matrices, respectively. $P(t)$ is the load matrix related to the pavement dynamic system. With considering a small damping question related to the asphalt pavement, Rayleigh damping theory is taken into account in this study.

Damping matrix can be written as a linear combination of stiffness and mass matrices, as follows:

$$
\{\mathrm{C}\}=\alpha\{\mathrm{M}\}+\beta(\mathrm{K})
$$

A popular spectral damping scheme used in the dynamic analysis, is Rayleigh damping. This model has a damping matrix $[\mathrm{C}]$ which is shown in Eq. (1). For multiple degrees of freedom systems, the critical damping ratio at any frequency of mode is given as equation. If both modes assumed to have the same damping ratio of $\xi$, Rayleigh coefficient can be used. The value of $\alpha$ and $\beta$ experimentally is 0.4 and 0.1 [15].

\subsection{Model Geometry}

Today, analysis and design of flexible pavement mainly based on powerful software including 2-D and 3-D finite element models are done. 3D models provide better responses than two-dimensional models and are closer to reality. Currently, in these designs changes is towards techniques to minimize restrictions in determining of the stress, strain and displacement in the pavement analysis [8]. Three-dimensional finite element analysis tools appeared to the best approach to respond significant fundamental issues in pavement implementation, however tedious process and the time required for accurate modeling of pavement systems prevented these analysis. Nowadays, finite element method plays an important role in engineering analysis. Version 6.11 of ABAQUS [1] software is used to analyze flexible pavement of roads [16]. Threedimensional model of the pavement structure in Abaqus software is shown in Fig. 1.

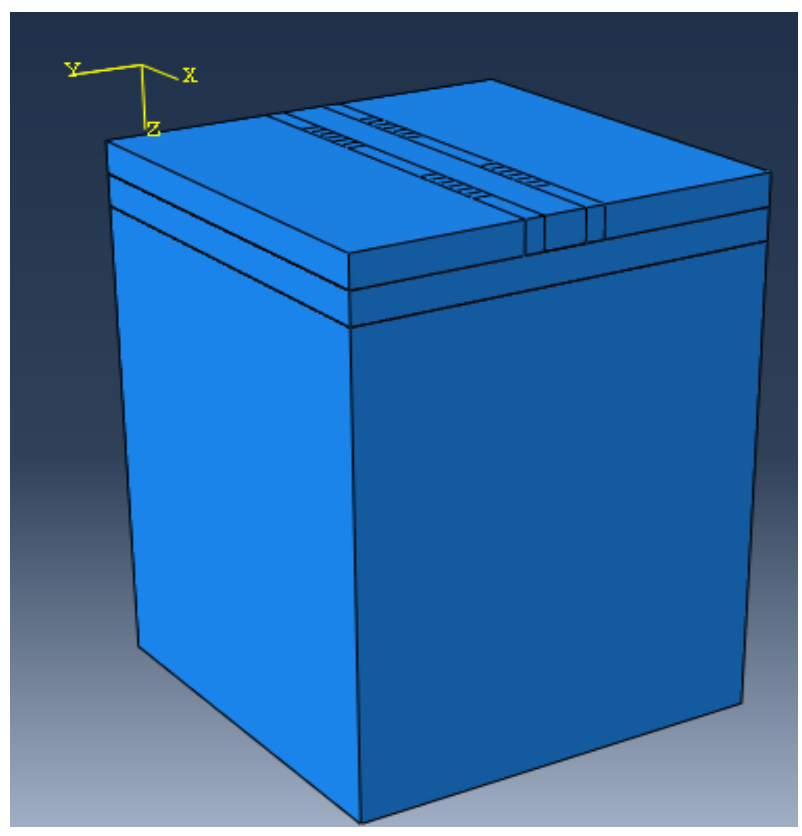

Fig. 1. Model geometry. 
For years, pavement design had been performed based on empirical-mechanistic methods in order to predict pavement responses (strain, stress and deformation) under traffic load and environmental conditions. Boundary conditions for finite element models highly affect on pavement responses. It is to be noted that selecting suitable boundary conditions directly affects accuracy of models [17]. Boundary conditions of the asphalt pavement including a clamped support at the bottom and two roller supports in two directions which can be seen in Fig. 2, two directions of the model are closed in horizontal direction and they are free in vertical direction. The sub-layer of pavement is closed in all directions [18 ].

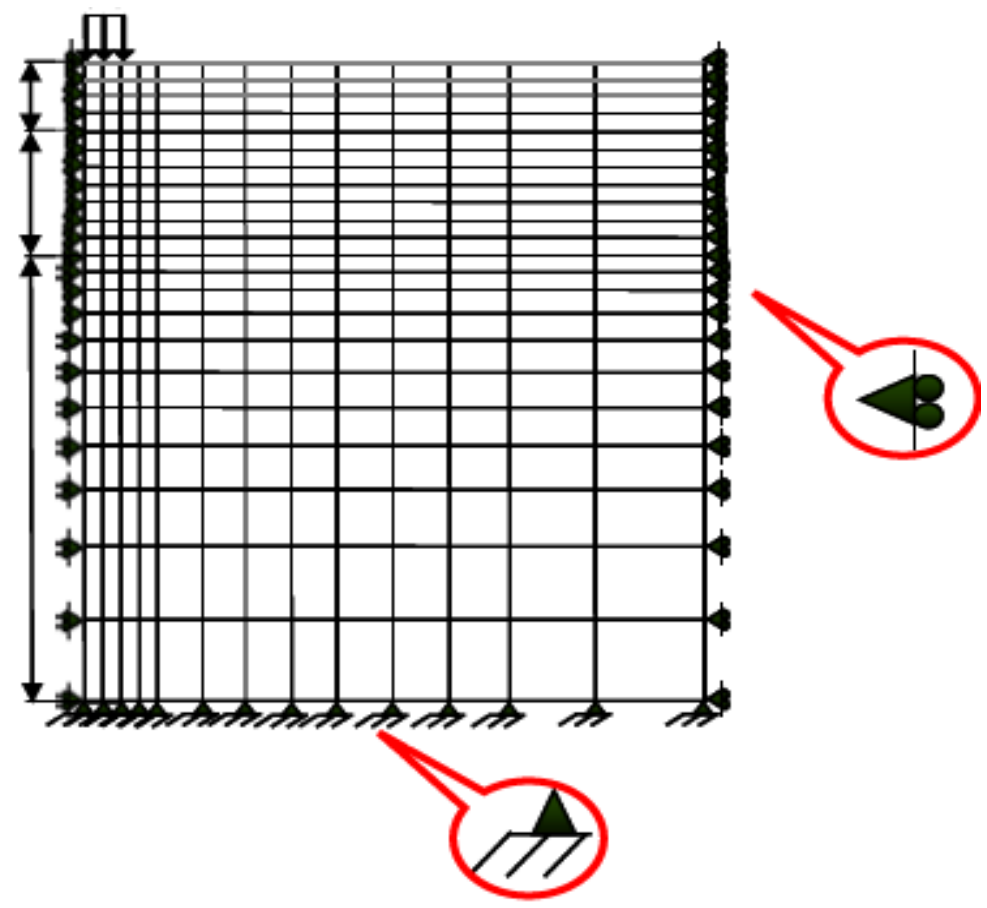

Fig. 2. Boundary conditions and loading.

Model meshing has been considered in a way to reach the best and most accurate results. One major conflict in finite elements model is to determine suitable size of elements meshes and model for pavement system [17]. 8 nodes linear brick reduced integration elements (C3D8R) meshing has been used to improve convergence rate [19].

Meshing should be designed in a way to provide good accuracy. All layers are meshed and the meshing should be done in a way to maintain consistency between the layers. The most important part of this modelling is around of the wheel loads in which stresses and displacement have highest value. Also, to increase the accuracy of this model, we choose coarse mesh in far areas and fine mesh in near areas. AlQadi and colleagues proposed that for the dynamic model, the best length of mesh in the loading area in thetransverse direction is $15-18(\mathrm{~mm})$ and in the longitudinal direction (traffic direction)is $20 \mathrm{~mm} .20 \times 20$ $(\mathrm{mm})$ square mesh for comfort meshing is considered [20].

In this paper, with 3D-pavement modelling we predict the asphalt behavior and performance in order to determine the coordinates of the maximum tensile strain in the asphalt sub-layer. In this study, the importance of the first asphalt layer to determine the coordinates of the maximum tensile strain is more and proposed fine meshing is applied to determine the exact result in this layer, the lower layers with coarse mesh analysis to increase the speed of analysis. Sub layers also analyzes with coarse meshing in order to increase the speed of analysis. In Fig. 3, model meshing is shown in Abaqus software. 


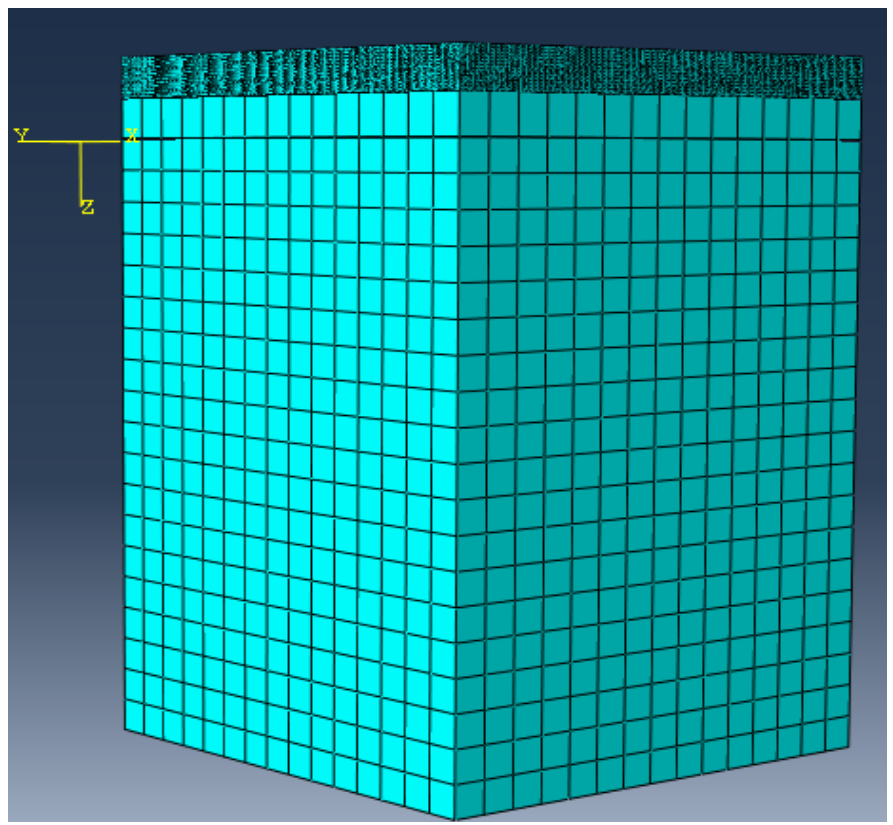

Fig. 3. Meshing.

\subsection{Validation}

Sebaaly et al. (1993) reported an extended full-scale field testing program, supported by Federal Highway Administration (FHWA). This program included installation of sensors to measure pavement strains under moving loads [21]. Two thick and thin pavement sections were considered for this study. The characteristics of thick pavement section are shown in Fig. 4. Pavement materials properties were estimated using FWD as shown in Table. 1. In this field testing, load of semi-trailer was measured by weight in motion system [21].

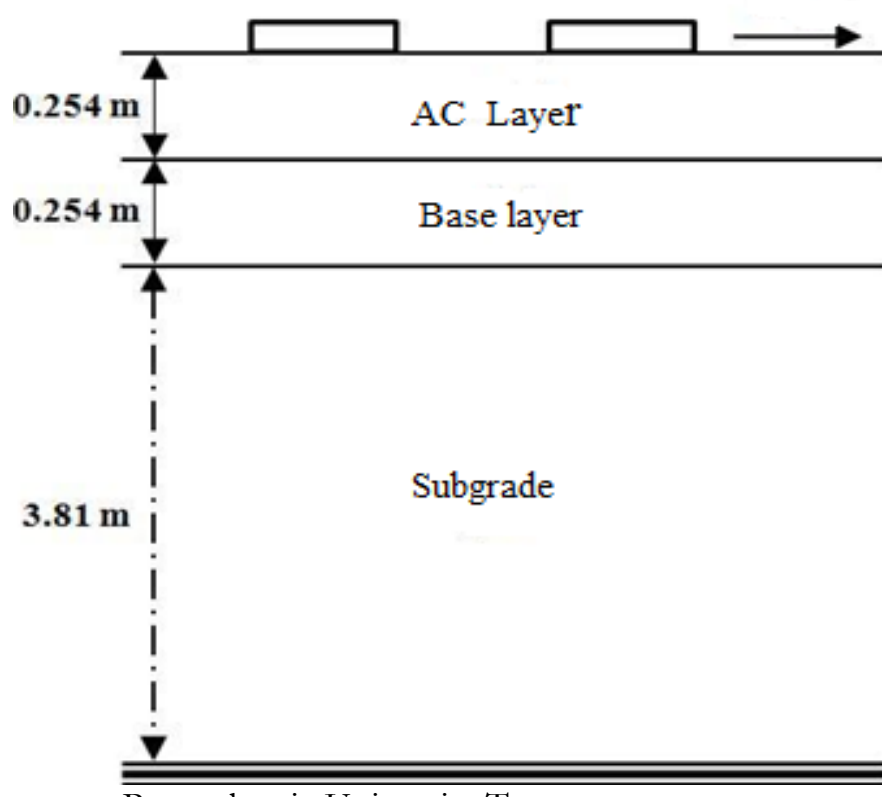

Fig. 4. Pavement Structure at Pennsylvania University Test.

The layer properties and characteristics were taken from Table 1 which is containing the elasticity modulus and thickness. In addition, the Poisson's ratio for the three layers of $0.3,0.35$ and 0.4 from top to bottom (surface, base and subgrade) were also selected respectively. 
Table 1. Characteristics of materials.

\begin{tabular}{lcc}
\hline Pavement layers & Thickness (meter) & Modulus of elasticity (MPa) \\
\hline Asphalt & 0.254 & 2550 \\
Base & 0.254 & 207 \\
Subgrade & 3.81 & 152 \\
\hline
\end{tabular}

In this field study, load-induced semi-trailer was measured by WIM systems. Load-induced semi-trailer has been considered in three levels of load including empty, half-full and full. For this test, velocities of 32, 56 and $80 \mathrm{~km} / \mathrm{h}$ were studied and longitudinal strain of asphalt sub layer was measured by Dynatest, Kyowa and Core sensors. Research results have shown that Core and Dynates tsensors provide the higher values of reality, sothe result of Kyowa sensor which is more valid was used for validation in this study.

Modeling has been done using Abaqus and 3d-move software. Figure 5 illustrates the relationship between the velocity and tensile strain of asphalt sub-layer.

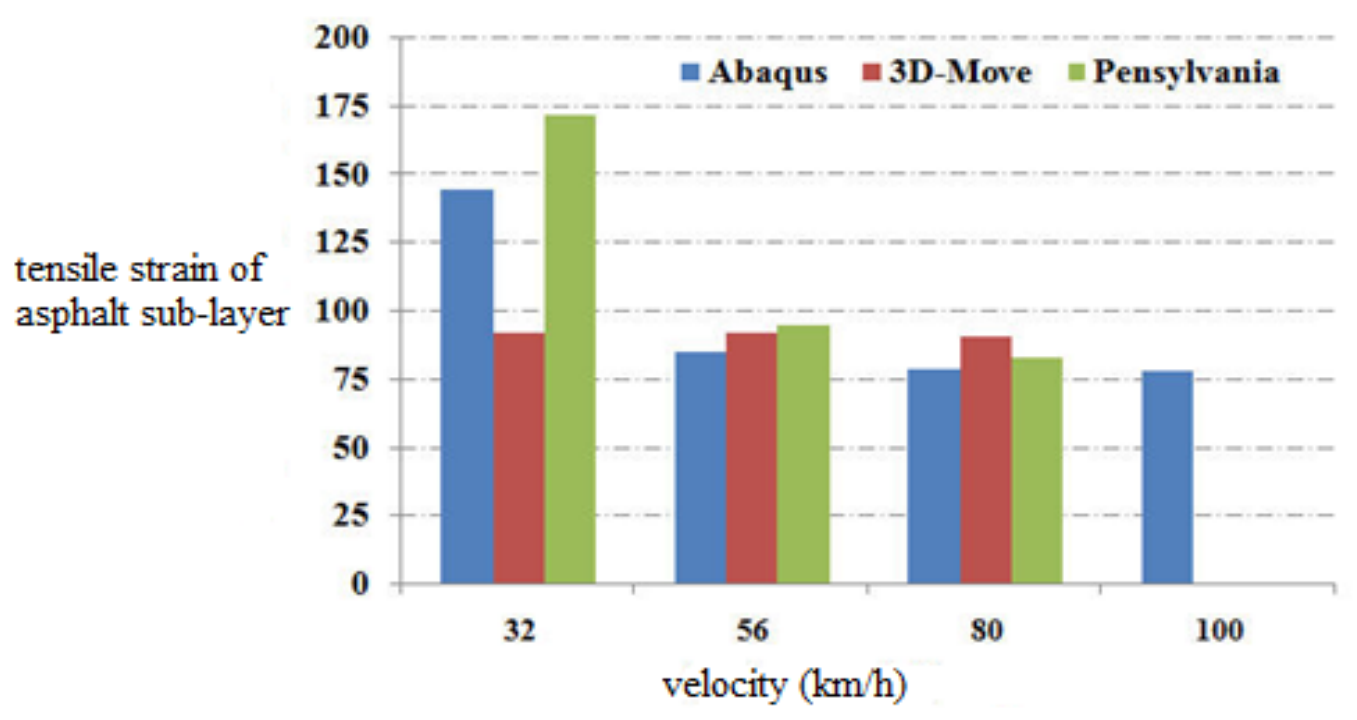

Fig. 5. The chart representation of velocity—longitudinal tensile strain of asphalt sub-layer.

Modeling shows that Abaqus has a better agreement with the Pennsylvania field results. 3D-Move software has a high speed of analysis, especially in the visco models, but it is not able to have strong dynamics analysis at low speeds. Abaqus software has a strong dynamic analysis power and one of the best software for dynamic analysis is the finite element method. The modeling was conducted by using Abaqus and the analysis of results will be discussed.

As can be seen, with increased velocity, tensile strain at the bottom of asphalt layer is reduced. In the following section of the study, the coordinates of the point in which the maximum strain occurs will be examined.

\subsection{The Effect of Elastic Modulus, Poisson's Ratio and Density on the Location of the Maximum Tensile Strain}

Flexible pavement design and analysis was done mainly based on empirical method using the elastic properties of the layers in the past. Elastic modulus and Poisson's ratio are the most important cases in determining the maximum stresses and strains. In this section, the effect of the elastic modulus and Poisson's ratio on the coordinates of the location of maximum tensile strain at the bottom of asphalt layer is investigated.

Modelling for various Poisson's ratio was also done and the results showed that Poisson's ratio do not affect the coordinates as well. The following chart shows the relationship between elasticity modulus and 
Coordinats of maximum tensile strain. The results of this study show that the elastic modulus and Poisson's ratio has no effect on the coordinates of the maximum tensile strain.

Research shows that for a fixed amount of load, changes in the density of road pavement materials does not change in pavement response. This occurs probably because the amount of load is not dependent on time. Figure 6 indicates the variation of elasticity modulus versus tensile strain at the bottom of asphalt layer.

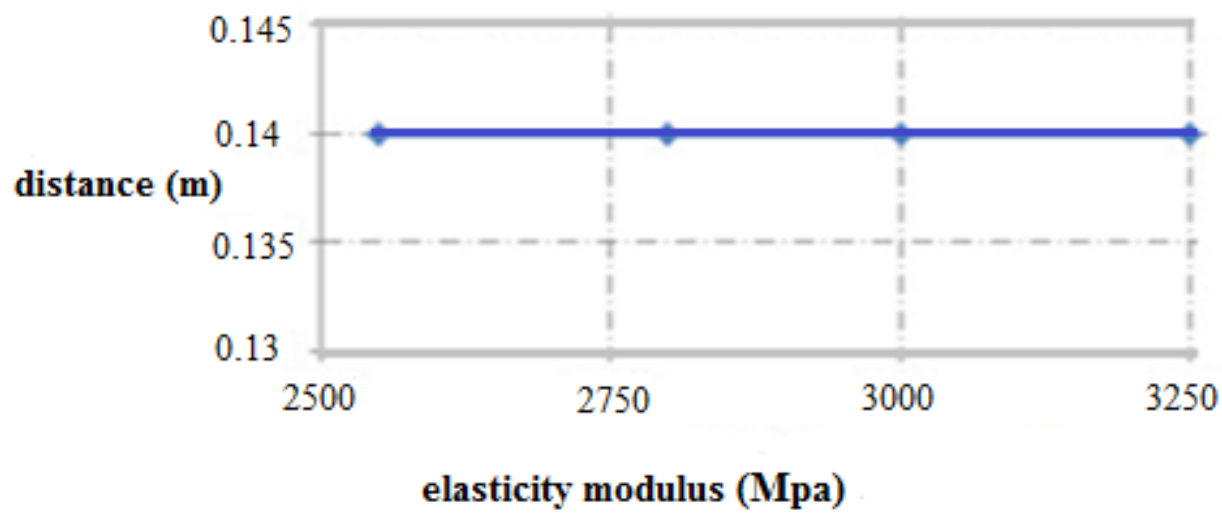

Fig. 6. Elasticity modulus - the coordinates of the maximum longitudinal tensile strain of asphalt sublayer.

\subsection{The Effect of Speed on the Location of Maximum Tensile Strain}

Figure 7 shows the longitudinal strain at the bottom asphalt layer at velocity of $32 \mathrm{~km} / \mathrm{h}$. As shown in the figure, the output of the software is deformed to the oval shape. In static mode, the focus of the color is in the form of a circle which its center coincide with the center of the wheel load and is the point of maximum strain.

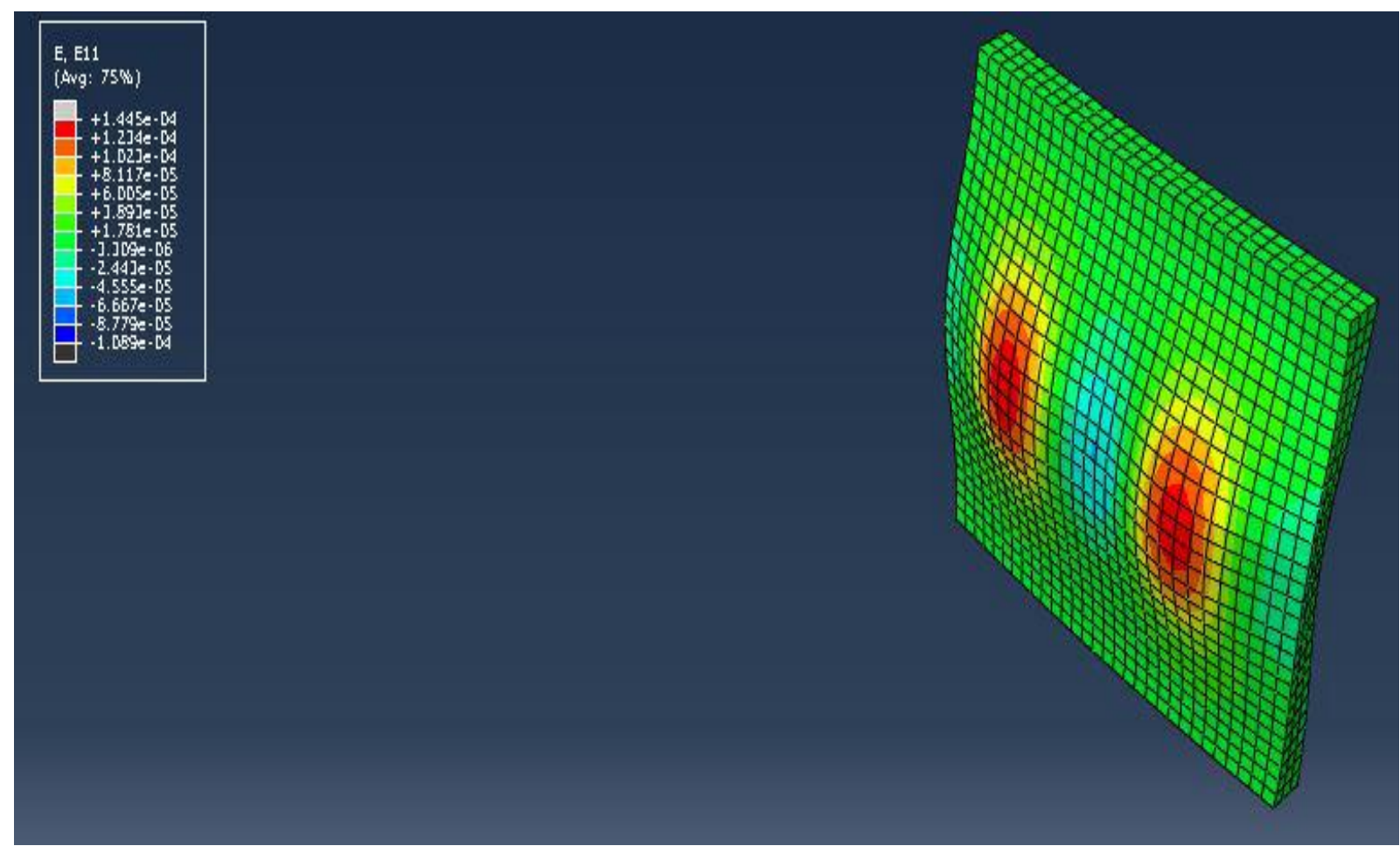

Fig. 7. Output of Abaqus (tensile strain at the bottom asphalt layer at speed of $32 \mathrm{~km} / \mathrm{h}$ ). 
As can be seen in Fig. 5, the oval in the opposite direction of traffic in modelling has a slight departure from the center. The distance is measured and as a function of velocity is given in Fig. 8. Strain diagram shows that the maximum strain unlike the static mode which occurred in the load center occurs behind the load center. The distance of the longitudinal tensile strains from the center is shown in Table 2.

Table 2. Determining the coordinates of the location of maximum strain under different velocities.

\begin{tabular}{lccccc}
\hline Velocity $(\mathrm{km} / \mathrm{h})$ & 0 & 32 & 56 & 80 & 100 \\
\hline $\begin{array}{l}\text { Coordinates of the maximum tensile strain } \\
\text { behind the load center }(\mathrm{m})\end{array}$ & 0 & 0.077 & 0.11 & 0.13 & 0.14 \\
\hline
\end{tabular}

As the velocity is reduced, the maximum strain value is closer to the center of the wheel, to the extent that at the velocity of zero the maximum strain is placed at the bottom of wheel center.

\section{Analysis of the Results and Estimating Equation to Simulate Other Speeds Considering Linear Elastic Behavior}

In Fig. 8, the graph of velocity and the distance from the load center for the maximum strain is plotted. According to the results, the curve fitted with the greatest precisionism depicted in Figure 8.

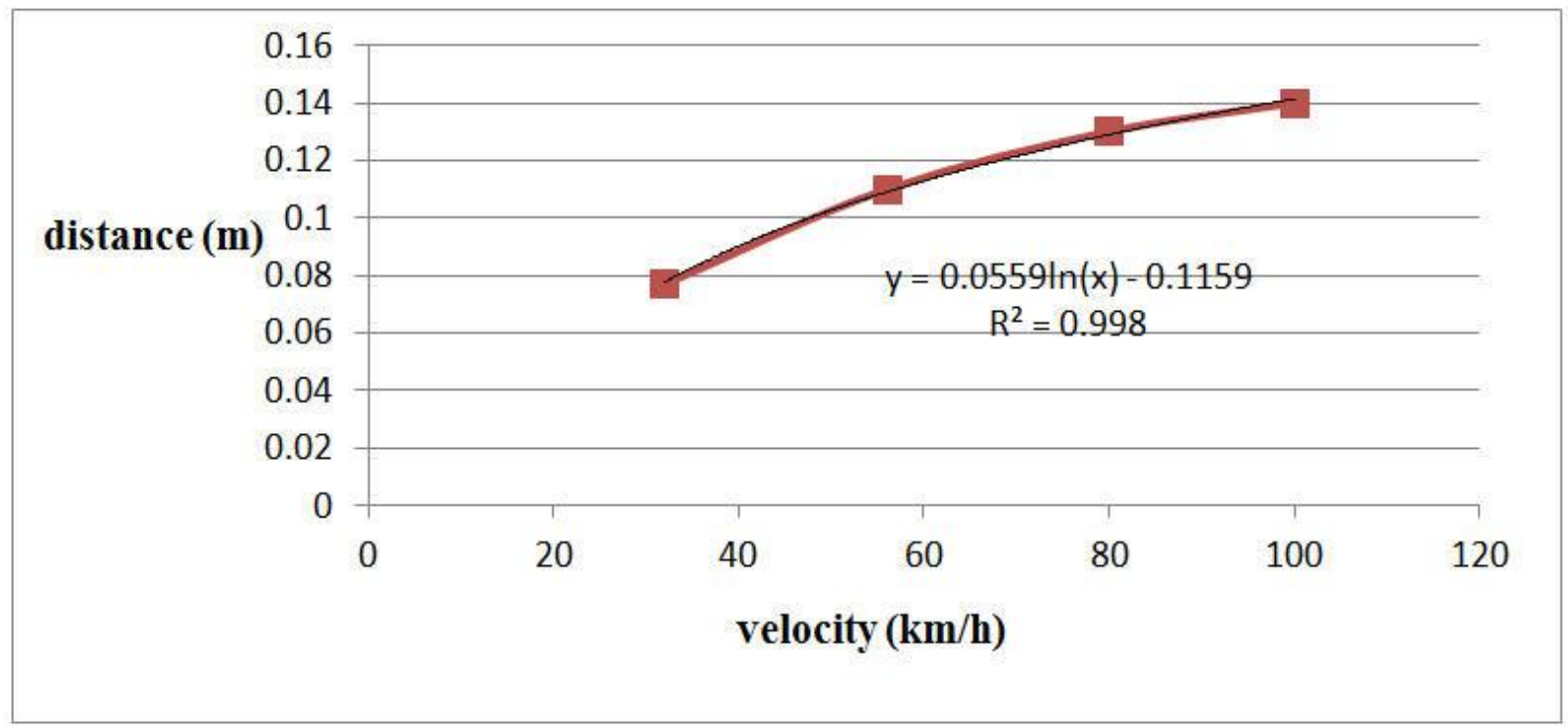

Fig. 8. Graph of velocity - the coordinates of the maximum longitudinal tensile strain of asphalt sublayer.

After considering the various factors affecting asphalt pavement response, the velocity was influencing factor in this research and new relationship is presented for coordinates of the maximum tensile strain of asphalt sub-layer in terms of velocity.

$$
\mathrm{U}=0 / 0551 \mathrm{n}(\mathrm{V})-0 / 115
$$

In the logarithmic equation presented, $\mathrm{V}$ (velocity) in terms of kilometers per hour and $\mathrm{U}$ is the distance from load center in terms of meters.

\section{Conclusion}

Changes in the density of road pavement materials will have no effect on the pavement response. In dynamic mode, due to the dependence of the dynamic equation on mass density is required.

$\checkmark \quad$ In static mode, the maximum strain occurs at the center of the load, but on the contrary, in dynamic mode this maximum value occurs behind of the load center.

$\checkmark \quad$ As the velocity is reduced, the maximum strain value is closer to the center of the wheel, to the extent that at the velocity of zero the maximum strain is placed at the bottom of wheel center. 
$\checkmark \quad$ The slope of graph decreases with increasing velocity. With increasing velocity, the distance from the center of the wheel becomes more, but with fewer changes going forward. Actually, the answer is more sensitive at lower velocities.

The results show that the density, Poisson's ratio and modulus of elasticity do not affect the coordinates of maximum location and velocity parameter influences these coordinates.

$\checkmark \quad$ Given the coordinates of the maximum does not depend on the other parameters and velocity has the greatest impact, the graph of Fig. 8 is plotted and a regression coefficient of 0/998, Logarithmic equation $\mathrm{U}=0 / 0551 \mathrm{n}(\mathrm{V})-0 / 115$ obtained, where $\mathrm{V}$ is velocity in terms of kilometer per hour and $\mathrm{U}$ is distance from the center of the load in terms of meters.

\section{References}

[1] L. Ging and A. Hudsonj, "Numerical methods in rock mechanic," International Journal of Rock and Mining, vol. 39 , pp. 409-427, 2002.

[2] Y. H .Huang, Pavement Analysis and Design. NJ: Prentice Hall, 1993.

[3] S. Zaghloul and T. White, "Use of a three dimensional, dynamic finite element program for analysis of flexible pavement," Transportation Research Record, TRB, Washington, D.C., pp. 60-69, 1993.

[4] D. H. Chen., M. Zaman, J. Laguros, and A. Soltani, "Assessment of computer programs for analysis of flexible pavement structure," Transportation Research Record 1482, TRB, National Research Council, Washington, D.C., pp. 123-133, 1995.

[5] N. D. Beskou and D. D. Theodor akopoulos, "Dynamic effects of moving loads on road pavements: A review," Soil Dynamics and Earthquake Engineering, vol. 31, pp. 547 -567, 2011.

[6] Y. Zhang and X. Zhang, "Dynamic response analysis of pavement and subgrade of highway," in Proc. Multimedia Technology (ICMT), IEEE International Conference, 2011, pp. 1034-1036.

[7] P. J. Yoo, I. L. Al-Qadi, and M. A. Elseifi, "In-situ validation of mechanistic pavement finite element modeling," Transportation Research Board 85th Annual Meeting, Washington, D.C., January 22-26, 2006.

[8] M. T. Rahman, K. Mahmud, and S. Ahsan, "Stress strain characteristics of flexible pavement using finite element analysis," International Journal of Structural Enginereing, vol. 2, no. 1, 2011.

[9] R. V. Siddharthan, J. Yao, and P. E. Sebaaly, "Pavement strain from moving dynamic 3D load distribution," Journal of Transportation Engineering, vol. 124, no. 6, pp. 557-566, 1998.

[10] J. P. Lourens, "Nonlinear dynamic analysis and design of road pavements," Department of Transport, Pretoria, South Africa, RR 90/030, 1992.

[11] M. S. Mamlouk and T. G. Davis, "Elasto-dynamic analysis of pavement deflections," Journal of Transportation Engineering, vol. 110, no. 6, pp. 536-550, 1984.

[12] M. S. A. Hardy and D. Cebon, "Response of continuous pavements to moving dynamic loads," Journal of Engineering Mechanics, vol. 119, no. 9, pp. 1762-1780, 1993.

[13] Y. Ozawa, J. Maina, and K. Matsui, "Linear elastic analysis of pavement structure loaded over rectangular area," Transportation Research Board 89th Annual Meeting, January 22-26, 2009, Washington, D.C.

[14] G. Shafabakhsh, A. Family, and B. Pourzand Hossein Abad, "Numerical analysis of concrete block pavements and comparison of its settlement with asphalt concrete pavements using finite element method," Engineering Journal, vol. 18, no. 4, pp. 39-51, 2014.

[15] G. Qian, J. Zheng, and H. Zhang, "Dynamic responses model of asphalt pavement under complex vehicle loads," in Proc. GeoHunan International Conference, pp. 96-102, 2009.

[16] HKS, ABAQUS Theory and User's Manual-Version 6.11. Pawttucket, Rhode Island: Hibbit, Karlsson \& Sorenson, Inc., 2005.

[17] A. Bayat and M. Knight, "Investigation of flexible pavement structural response for the Centre for Pavement and Transportation Technology (CPATT) test road," Transportation Research Board 89th Annual Meeting, 2010.

[18] G. Wang, R. Roque, and D. Morian, "Evaluate near-surface stress states in AC pavement based on 3D tire-pavement contact model," Transportation Research Board, 2011.

[19] M. N. S. Hadi and B. C. Bodhinayake, "Non-linear finite element analysis of flexible pavements," Advances in Engineering Software, vol. 34. pp. 657-662, 2003. 
[20] I. L. Al-Qadi and P. J. Yoo, (2008) "Truth and myth of fatigue cracking potential in hot-mix asphalt: Numerical analysis and validation," Journal of Association of Asphalt Paving Technologists, vol. 77, pp. 549_ 590, 2008.

[21] P. E. Sebaaly, N. Tabatabaie, B. T. Kulakowaski, and T. Scullion, "Instrumentation for flexible pavements-field performance of selected sensors," Final Report, vol. I and II, FHWA, Report No. FHWA-RD-91-094, 1993. 